\title{
A novel antibacterial peptide family isolated from the silkworm, Bombyx mori
}

\author{
Seiichi HARA* and Minoru YAMAKAWA † \\ *Noda Institute for Scientific Research, Noda, Chiba 278, Japan and †Laboratory of Biological Defense, National Institute of Sericultural and Entomological Science, \\ Tsukuba, Ibaraki 305, Japan
}

Three structurally related and novel antibacterial peptides have been isolated from the haemolymph of the silkworm, Bombyx mori, immunized with Escherichia coli. These peptides were 32 amino acids long and characteristically rich in proline residues. A unique threonine residue in each peptide was $\mathrm{O}$-glycosylated and the modification seemed to be important for expression of antibacterial activity. The primary structure and antibacterial character of the novel peptides resemble those of abaecin $(41 \%$ identity in amino acid sequence), an antibacterial peptide of the honeybee, although abaecin is not O-glycosylated. Incubation of the novel peptides with a liposome preparation caused leakage of entrapped glucose under low-ionic-strength conditions, suggesting that a target of the peptides is the bacterial membrane. We propose the name 'lebocin' for the novel peptide family isolated from $B$. mori.

\section{INTRODUCTION}

Although the insect immune system does not involve antigenantibody reactions, insects have efficient self-defence mechanisms against bacterial infection; for example, induction of antibacterial peptides [1]. To date, many antibacterial peptides have been isolated from different species of insects [2] and can be classified into five major groups [3]: cecropins, insect defensins, attacin-like proteins, proline-rich peptides and lysozymes. Of these, defensins were originally found in vertebrates [4-8]. In 1989, a dipteran insect, Phormia terranovae, was reported to have defensin-type antibacterial peptides [9]. Similarly, cecropin, originally isolated from the lepidopteran Hyalophora cecropia, has been also found in pig intestine [10]. These results suggest that insects and vertebrates may share a common immune system against bacterial infection. Therefore insects can provide good model systems for studying the self-defence mechanisms mediated by antibacterial peptides against bacterial invasion in animals.

Usually when insects are infected with bacteria or are injured, antibacterial peptides are induced rapidly and simultaneously [3], suggesting that the network of antibacterial peptides plays an important role in eliminating different types of invading bacteria. To understand the role of such a network in defence against bacterial infection, it is important to identify individual peptides. We have recently analysed antibacterial fractions from the immunized haemolymph of the silkworm, Bombyx mori [11]. In $B$. mori, only cecropins and lysozyme have been reported as antibacterial peptides $[1,12-14]$.

In the present work, we investigated one of the uncharacterized antibacterial fractions and found a novel antibacterial peptide family. The peptides were characteristically rich in proline residues and contained a unique $\mathrm{O}$-glycosylated threonine residue. The novel peptides resembled abaecin, an antibacterial peptide from honeybee [15], and increased the permeability of liposomal membrane under conditions of low ionic strength.
This is the first proline-rich antibacterial peptide found in a lepidopteran insect.

\section{MATERIALS AND METHODS}

\section{Immunization and collection of haemolymph}

B. mori (Tokai $\times$ Asahi) were reared on an artificial diet (Nihonnosanko, Yokohama, Japan) at $25^{\circ} \mathrm{C}$. Fifth-instar larvae were immunized with Escherichia coli $\mathrm{HB} 101$, and the haemolymph was collected into a $50 \mathrm{ml}$ centrifuge tube and heattreated as described previously [16].

\section{Purlification procedures}

Antibacterial substances were separated essentially as previously described [11]. Briefly, solid $\left(\mathrm{NH}_{4}\right)_{2} \mathrm{SO}_{4}$ was added to the haemolymph, and material precipitating between 15 and $75 \%$ $\left(\mathrm{NH}_{4}\right)_{2} \mathrm{SO}_{4}$ saturation was collected and subjected to gel filtration on a column of Sephadex G-50 (Pharmacia-LKB, Uppsala, Sweden) with $50 \mathrm{mM}$ ammonium acetate, $\mathrm{pH}$ 5, as elution buffer. The eluted antibacterial peak was pooled and loaded on to a cation-exchange column of CM-Toyopearl 650M (Tosoh, Tokyo, Japan). After the column had been washed with the same buffer, material was eluted with an ammonium acetate gradient [0.05 M (pH 5)-0.15 M (pH 7)].

The antibacterial peak eluted just after the mature cecropin D from the cation-exchange column [11] was pooled and lyophilized. The lyophilisate was dissolved in a small amount of water and loaded on to a reverse-phase HPLC column (4.6 $\mathrm{mm} \times 250 \mathrm{~mm}$ ) of Capcell Pak $\mathrm{C}_{8}$ SG300 (Shiseido, Tokyo, Japan) which was connected to a Shimazu LC-6A HPLC system. The column was equilibrated with $28 \%$ acetonitrile $/ 0.1 \%$ trifluoroacetic acid (TFA), and eluted with a linear gradient of $28-40 \%$ acetonitrile containing $0.1 \%$ TFA over $25 \mathrm{~min}$ at a flow 
rate of $0.5 \mathrm{ml} / \mathrm{min}$; absorbance was monitored at $220 \mathrm{~nm}$. Each absorbance peak with antibacterial activity was subjected to reverse-phase HPLC again using the same column and conditions except that the column was previously equilibrated with $12 \%$ acetonitrile/0.1\%TFA. After the loading of a sample, the column was washed for 5 min with $12 \%$ acetonitrile $/ 0.1 \%$ TFA, and then the acetonitrile concentration was raised to $28 \%$ over 3 min. Peptides were eluted with a linear gradient of $28-36 \%$ acetonitrile containing $0.1 \%$ TFA over $38 \mathrm{~min}$. The reversephase HPLC was carried out at room temperature.

\section{Assay for antibacterial activity}

During the purification of these novel antibacterial peptides, the conditions for the growth-inhibition-zone assay [17] were modified as follows to increase the sensitivity of the assay. Acinetobacter sp. NISL B-4653, a strain isolated and kept in one of our laboratories, was used as an indicator, and the assay plates of nutrient medium (Eiken Chemical, Tokyo, Japan) contained $1 \%(w / v)$ Triton X-100 (Nacalai Tesque, Kyoto, Japan). When antibacterial activity was evaluated by the growth-inhibitionzone assay under normal conditions, plates of nutrient medium (Difco, Detroit, MI, U.S.A.) without Triton X-100 were used.

\section{Electrophoresis}

SDS/PAGE (16.5\% gels) for low-molecular-mass proteins was carried out as described by Schägger and von Jagow [18]. A molecular-mass marker kit (MW-SDS-17S; Sigma, St. Louis, MO, U.S.A.) was used to provide standards.

\section{Amino acid sequencing}

After SDS/PAGE, the peptides were transferred to poly(vinylidene difluoride) membrane (Applied Biosystems) and amino acid sequences determined on a protein sequencer (Applied Biosystems 473A).

\section{Sugar analysis}

A sample of $100-150 \mathrm{pmol}$ of glycopeptide was hydrolysed in vacuo for $4 \mathrm{~h}$ at $100^{\circ} \mathrm{C}$ with $2 \mathrm{M} \mathrm{HCl}$ and $2 \mathrm{M}$ TFA. Free amino groups were acetylated, and liberated sugars were subjected to pyridylamination as described previously [19]. The fluorescent pyridylaminosugars obtained were analysed by HPLC on an anion-exchange column ( $4.6 \mathrm{~mm} \times 150 \mathrm{~mm}$ of PALPAK Type A) (Takara, Kyoto, Japan). The column was eluted with $0.7 \mathrm{M}$ boric acid [adjusted to $\mathrm{pH} 9$ with $\mathrm{KOH} /$ acetonitrile $(9: 1, \mathrm{v} / \mathrm{v})$ ] at a flow rate of $0.3 \mathrm{ml} / \mathrm{min}$. Excitation and emission wavelengths were $310 \mathrm{~nm}$ and $380 \mathrm{~nm}$ respectively.

\section{Glycosidase digestion}

A glycopeptide sample $(10 \mu \mathrm{g})$ was digested with $0.5 \mathrm{~m}$-unit of endo- $\alpha-N$-acetylgalactosaminidase from Diplococcus pneumoniae (Takara) in $100 \mu \mathrm{l}$ of $75 \mathrm{mM}$ phosphate buffer, $\mathrm{pH} \mathrm{6}$, for $20 \mathrm{~h}$ at $37^{\circ} \mathrm{C}$. The same amount of sample was also digested with $25 \mathrm{~m}$ units of $\alpha-N$-acetylgalactosaminidase from Acremonium sp. (Seikagaku Corp., Tokyo, Japan) in $100 \mu \mathrm{l}$ of $50 \mathrm{mM}$ citrate buffer, $\mathrm{pH} 4.5$, for $20 \mathrm{~h}$ at $37^{\circ} \mathrm{C}$. The reaction mixtures were acidified with acetic acid and subjected to reverse-phase HPLC. Elution conditions were as described above.

\section{Synthetic peptides}

Peptides corresponding to the peptide moiety of the glycopeptides were chemically synthesized (Millipore; 9050Plus) and purified by reverse-phase HPLC on a column $(10 \mathrm{~mm} \times 250 \mathrm{~mm})$ of Capcell Pak $\mathrm{C}_{8}$ SG300. Their amino acid sequences were confirmed by using the same protein sequencer as described above.

\section{Liposome preparation and membrane-permeability assay}

Liposomes with trapped glucose were prepared as described by Yamada and Natori [20]; the phospholipid composition was similar to that of $E$. coli: the molar ratio of phosphatidylethanolamine/phosphatidylglycerol/cardiolipin was 7:2:1 (by mol.). Briefly, $2 \mu \mathrm{mol}$ of the mixture of phospholipids in chloroform was dried in a glassware test tube under nitrogen gas. Then $0.2 \mathrm{ml}$ of $0.3 \mathrm{M}$ glucose was added and multilamellar liposomes were made by vortexing. The liposome preparation obtained was washed three times with $1 \mathrm{ml}$ of $10 \mathrm{mM}$ sodium phosphate buffer (with or without $130 \mathrm{mM} \mathrm{NaCl}$ ), $\mathrm{pH} \mathrm{7,} \mathrm{to} \mathrm{remove} \mathrm{untrapped}$ glucose, and finally suspended in $0.6 \mathrm{ml}$ of the same buffer.

Liposome suspension $(15 \mu \mathrm{l})$ was added to various amounts of peptides dissolved in $15 \mu \mathrm{l}$ of $10 \mathrm{mM}$ sodium phosphate buffer (with or without $130 \mathrm{mM} \mathrm{NaCl}$ ), pH 7, and then the mixtures were incubated at $25^{\circ} \mathrm{C}$ for $1 \mathrm{~h}$. The amount of glucose released from the liposome preparation was assayed with a Glucose CTest kit (Wako Chemical, Osaka, Japan).

Phosphatidylethanolamine from E. coli, phosphatidylglycerol from egg yolk lecithin, cardiolipin from bovine heart and $\alpha$ lactalbumin from bovine milk were obtained from Sigma.

\section{RESULTS}

\section{Purification of novel antibacterial peptides}

During the purification step of cation-exchange chromatography on a column of CM-Toyopearl, cecropin D was eluted first as described elsewhere [11]. Initial efforts to purify antibacterial material from the antibacterial peak fraction eluted just after

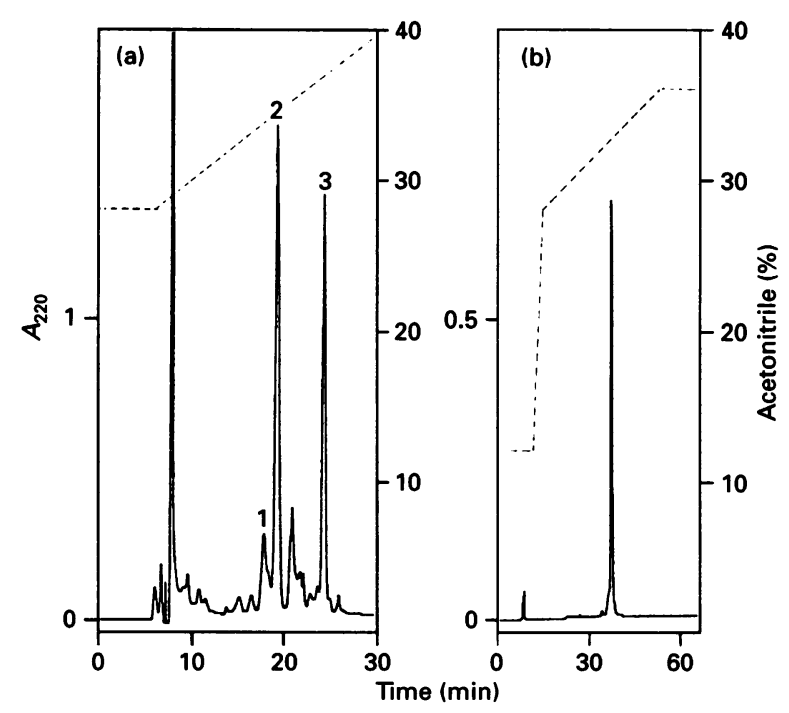

Figure 1 Purification of novel antibacterial peptides by reverse-phase HPLC

A sample containing the antibacterial peak eluted just after the mature cecropin $D$ on cationexchange chromatography [11] was subjected to reverse-phase HPLC (a). Peak 2 was again subjected to reverse-phase HPLC for further purification (b). Peaks 1 and 3 were also subjected to chromatography in the same manner. The column was eluted with a gradient of acetonitrile $(---)$ containing $0.1 \%$ TFA, and absorbance was monitored at $220 \mathrm{~nm}(-)$. Experimental details are given in the Materials and methods section. 


\section{Table 1 Amino acid composition of peptides 1, 2 and 3}

Peptides were hydrolysed in vacuo for $24 \mathrm{~h}$ at $110^{\circ} \mathrm{C}$ with $6 \mathrm{M} \mathrm{HCl}$ containing $0.1 \%$ phenol, and the hydrolysate was analysed with a Hitachi model 835-50 amino acid analyser. The numbers in parentheses are taken from amino acid sequencing data.

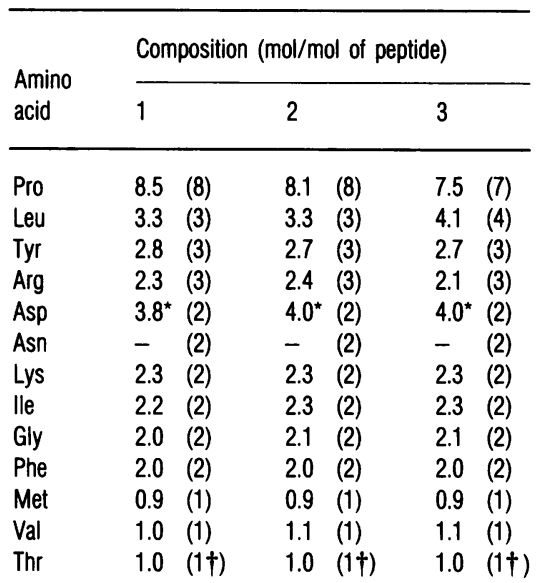

* Including the corresponding amide.

$\dagger$ Detected in the deglycosylated peptide.

cecropin D failed because of its very low antibacterial activity. Therefore we established more sensitive assay conditions as described in the Materials and methods section so that the activity of the peak could be easily detected. The antibacterial peak was then subjected to reverse-phase HPLC. Figure 1(a) shows a typical elution profile. The two major peaks, 2 and 3, shared most of the antibacterial activity and were further purified by rechromatography (reverse-phase HPLC). Figure 1(b) shows a typical elution pattern obtained by rechromatography of peak 2. Peaks 2 and 3 and the major stained band of peak 1 migrated to the same position $(5.5 \mathrm{kDa})$ on SDS/PAGE (results not shown), suggesting that the three peptides have similar molecular masses. Peak 1 was also subjected to rechromatography. We designated the three peptides 1,2 and 3 on the basis of their elution order during the first reverse-phase HPLC step (Figure 1a). From $200 \mathrm{ml}$ of immunized $B$. mori haemolymph, we obtained about 60,300 and $240 \mu \mathrm{g}$ of peptides 1,2 and 3 respectively; their concentrations were measured by the folin/phenol method [21].

\section{Structural analysis of the peptides}

The amino acid compositions of the three peptides were similar to each other (Table 1), but very different from those of cecropins from $B$. mori. Characteristically, the novel peptides were rich in proline, which made up about a quarter of the total amino acid residues.

The amino acid sequences of the novel peptides were determined using $2 \mathrm{nmol}$ of each peptide. Peptides 1 and 2 had the same amino acid sequence as follows: Asp-Leu-Arg-Phe-LeuTyr-Pro-Arg-Gly-Lys-Leu-Pro-Val-Pro-Xaa-Pro-Pro-Pro-PheAsn-Pro-Lys-Pro-Ile-Tyr-Ile-Asp-Met-Gly-Asn-Arg-Tyr. In peptide 3 , the sequence was the same except that residue 16 (proline) was replaced by leucine. During Edman degradation each peptide gave an ambiguous or no signal for the phenylthiohydantoin-amino acid at residue 15 , so this residue could not be identified by Edman degradation alone. However, the results of the amino acid composition analysis suggested the existence of one threonine in each peptide (Table 1). Therefore we presumed that residue 15 was threonine with some modification.

\section{Analysis of the modlifed structure}

In preliminary experiments, we found that the isolated peptides could be oxidized by mild periodate treatment (results not shown), suggesting the presence of sugars. The molecular masses of the peptides were measured by ion-spray MS. The calculated (assuming that residue 15 is threonine without modification) and measured masses are listed in Table 2. All three peptides had larger masses than calculated. For peptide 1, the mass difference was $365.3 \mathrm{Da}$. The addition of $1 \mathrm{~mol}$ of $\mathrm{N}$-acetylhexosamine (221.2 Da) plus $1 \mathrm{~mol}$ of hexose $(180.2 \mathrm{Da})$ to the peptide (assuming the loss of $2 \mathrm{~mol}$ of water) by O-glycosylation of threonine could explain the difference in mass. For peptides 2 and 3 , the addition of $1 \mathrm{~mol}$ of $\mathrm{N}$-acetylhexosamine by $\mathrm{O}$ glycosylation of threonine was similarly predicted. To confirm these possibilities and to identify what kind of sugar binds to the peptides, we analysed the sugar composition of each peptide as described in the Materials and methods section. The results showed that peptide 1 contained GalNAc and Gal, and that peptides 2 and 3 contained GalNAc (Figure 2). The results of MS and sugar analysis indicated that peptide 1 contained $1 \mathrm{~mol}$ of GalNAc plus $1 \mathrm{~mol}$ of $\mathrm{Gal}$ and that peptides 2 and 3 contained $1 \mathrm{~mol}$ of GalNAc.

The presence of the sugar residues and their linkage to threonine were confirmed by reaction with glycosidases. First, two peptides designated S2 and S3 were synthesized: peptide S2 corresponded to the peptide moiety of peptides 1 and 2 , and peptide S3 to the peptide moiety of peptide 3. Peptide 1 was incubated with endo- $\alpha-N$-acetylgalactosaminidase, an enzyme that specifically releases Gal $\beta 1-3 \mathrm{GalNAc}$ from glycoproteins that possess Gal $\beta 1-3 \mathrm{GalNAc} \alpha 1-\mathrm{Thr} / \mathrm{Ser}$ moieties [22], and subjected to reverse-phase HPLC. The retention time of the enzyme-treated peptide was slower than that of the untreated peptide, but the same as that of the synthetic peptide S2, indicating that the $\mathrm{O}$-glycosylation structure of peptide 1 is Gal $\beta 1-3$ GalNAc $\alpha 1-T h r$. Peptides 2 and 3 were treated with $\alpha-N$ acetylgalactosaminidase, an enzyme that specifically cleaves the $\alpha$-linkage of GalNAc present at the non-reducing end of a sugar chain [23]. The retention times of each of the enzyme-treated peptides were slower than those of the untreated peptides, but the same as those of synthetic peptides $S 2$ and $S 3$ respectively, indicating that GalNAc is linked to peptides 2 and 3 by an $\alpha$ linkage. Finally, the enzyme-treated peptides were subjected to automated Edman degradation. The results showed that residue 15 of each deglycosylated peptide was threonine (results not shown).

\section{Table 2 Molecular masses of peptides 1, 2 and 3}

Molecular masses were measured by ion-spray MS on a Sciex model API-III triple-quadrupole spectrometer. The calculated mass is the average mass value assuming that residue 15 is an unmodified threonine residue. The standard deviation of measured mass was 0.4 .

\begin{tabular}{llll}
\hline \multirow{4}{*}{ Molecular mass $(\mathrm{Da})$} \\
\cline { 2 - 4 } Peptide & Calculated & Measured & Difference \\
\hline 1 & & & \\
2 & 3773.5 & 4138.8 & 365.3 \\
3 & 3773.5 & 3976.1 & 202.6 \\
& 3789.5 & 3992.4 & 202.9
\end{tabular}



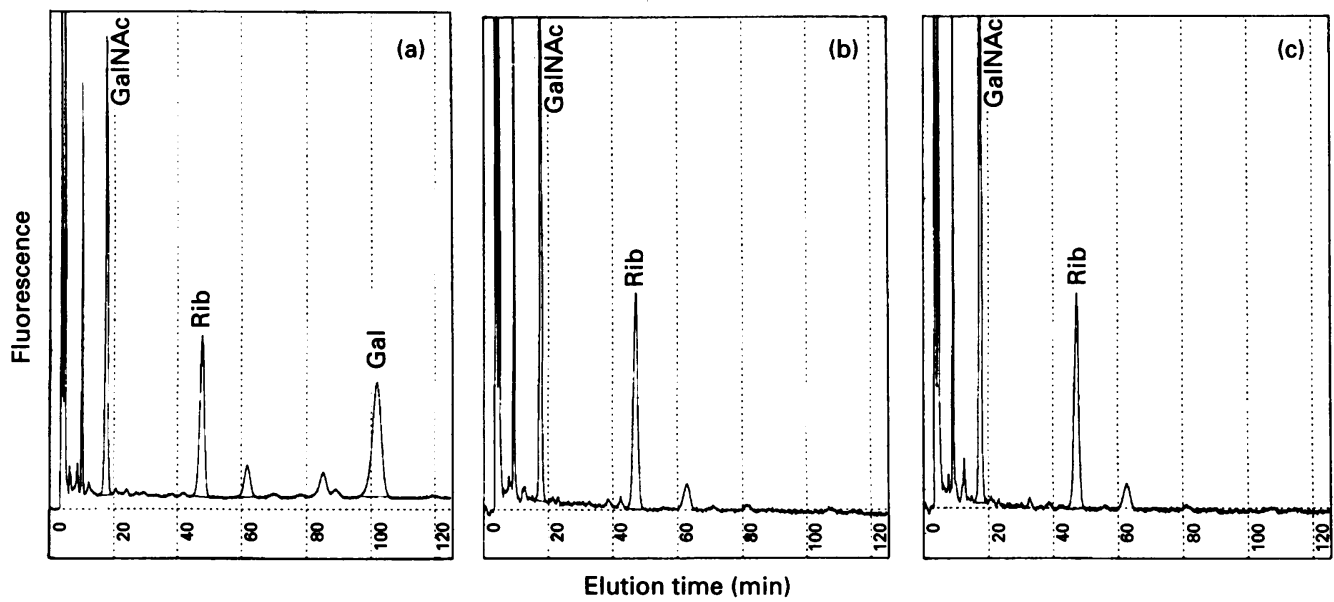

\section{Figure 2 Sugar analysis of peptides 1, 2 and 3}

Each peptide sample was hydrolysed, and liberated sugars were subjected to pyridylamination. Material derived from 100 pmol of peptide 1 (a), 150 pmol of peptide 2 (b) and 150 pmol of peptide 3 (c) was analysed by anion-exchange HPLC and the fluorescent peak was identified by comparing the retention time with those of pyridylamino-monosaccharide standards. Ribose was added to the hydrolysate as an internal standard.

\section{Table 3 Antibacterial activity of isolated and synthetic peptides}

The growth-inhibition-zone assay [17] was performed on assay plates of nutrient medium. Well diameter was $2 \mathrm{~mm}$ and the value $2 \mathrm{~mm}$ indicates the formation of no inhibition zone. Values are means \pm S.D. of three experiments. n.d., Not determined. Synthetic peptides S2 and S3 do not contain sugar chains and correspond to peptides 2 and 3 respectively. Cecropin $B_{1}$ isolated from B. mori was used as a control antibacterial peptide.

\begin{tabular}{|c|c|c|c|c|c|c|c|}
\hline \multirow[b]{2}{*}{ Bacteria } & \multirow{2}{*}{$\begin{array}{l}\text { Amount } \\
\text { (nmol/well) }\end{array}$} & \multicolumn{6}{|c|}{ Inhibítion-zone ditameter (mm) } \\
\hline & & 1 & 2 & 3 & S2 & S3 & Cecropin $B_{1}$ \\
\hline Acinetobacter $\mathrm{sp}$. & 2 & $2.3 \pm 0.6$ & $4.0+0.2$ & $4.8+0.1$ & 2 & 2 & n.d. \\
\hline NISL B-4653 & 0.5 & 2 & $2.8 \pm 0.1$ & $3.0 \pm 0.1$ & 2 & 2 & $11.8 \pm 0.1$ \\
\hline E. coli & 2 & $2.5 \pm 0.3$ & $3.6 \pm 0.1$ & $4.6 \pm 0.3$ & $2.6 \pm 0.3$ & $2.1 \pm 0.1$ & n.d. \\
\hline HB101 & 0.5 & 2 & 2 & $2.2 \pm 0.1$ & 2 & 2 & $15.1 \pm 0.3$ \\
\hline Pseudomonas & 2 & 2 & 2 & $2^{-}$ & 2 & 2 & n.d. \\
\hline fluorescens IAM1179 & 0.5 & 2 & 2 & 2 & 2 & 2 & $13.6 \pm 0.1$ \\
\hline Staphylococcus aureus & 2 & 2 & 2 & 2 & 2 & 2 & n.d. \\
\hline ATCC6538P & 0.5 & 2 & 2 & 2 & 2 & 2 & $11.2 \pm 0.1$ \\
\hline
\end{tabular}

\section{Antibacterial activity of the novel peptides}

The antibacterial activities of the isolated and synthetic peptides against various bacteria were compared by the growth-inhibitionzone assay [17]. Peptides 1,2 and 3 showed antibacterial activity against the two Gram-negative bacteria, Acinetobacter sp. and $E$. coli (Table 3). Peptide 3 had the highest activity against the two bacteria followed by peptide 2 . Synthetic peptides S2 and S3 showed much less or no activity compared with the natural ones, indicating that O-glycosylation is important for the full expression of antibacterial activity. However, elongation of the sugar chain tended to reduce activity (compare peptide 1 with peptide 2).

As shown in Table 3, the antibacterial activity of the novel peptides was much lower than that of cecropin $B_{1}$, an antibacterial peptide from $B$. mori [12]. It was possible that the antibacterial activity of the novel peptides was inhibited by salt as is the case for abaecin, a proline-rich antibacterial peptide from honeybee [15]. In preliminary experiments, the peptides at a concentration of the order of $10 \mu \mathrm{g} / \mathrm{ml}$ showed bactericidal activity against $E$. coli when incubated in water. However, they showed only slight activity when incubated in the presence of a salt, such as $\mathrm{NaCl}$, $\mathrm{KCl}, \mathrm{MgCl}_{2}, \mathrm{NaNO}_{3}$ and $\mathrm{Na}_{2} \mathrm{SO}_{4}$. Sucrose did not have much effect on the antibacterial activity of the peptides, suggesting that the decrease in activity caused by salt was not due to osmotic stabilization of the bacteria but was due to inhibition of the adsorption of the peptides to the bacterial surface, which is mediated by ionic interactions [24].

\section{Effect of the novel peptides on the permeability of liposomal membrane}

The peptides were isolated by monitoring their activity using assay plates containing $1 \%$ Triton $\mathrm{X}-100$. There was a possibility that the peptides might affect the permeability of bacterial membrane, because the growth of intact Acinetobacter cells was not affected very much by $1 \%$ Triton X-100 alone. The possibility 


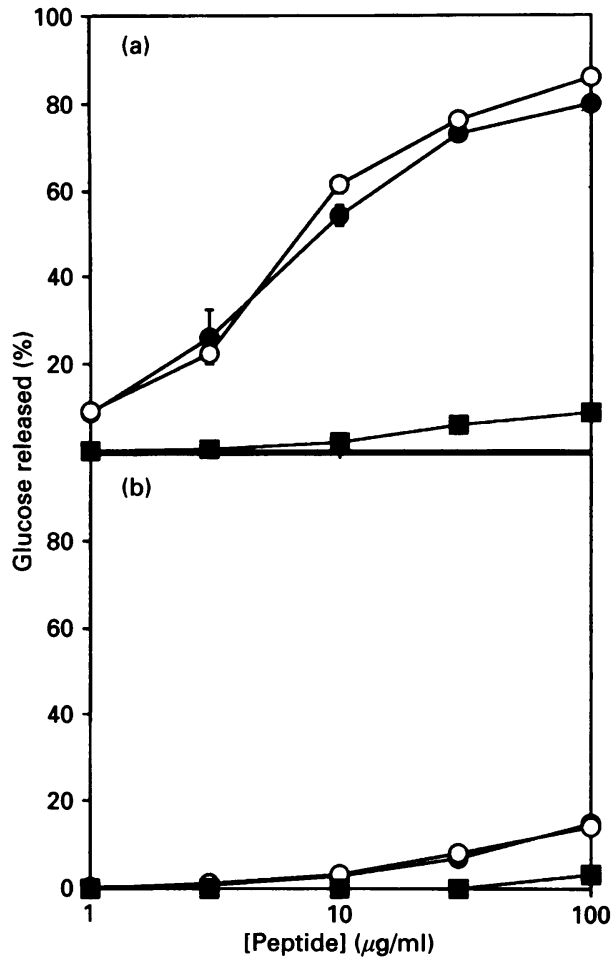

Figure 3 Effects of the peptides on liposomal membrane permeability

E. coli-type liposomes with entrapped glucose were prepared and incubated with different concentrations of peptides in $10 \mathrm{mM}$ sodium phosphate, $\mathrm{pH} 7$ (a) or in $10 \mathrm{mM}$ sodium phosphate, $\mathrm{pH} \mathrm{7}$, containing $130 \mathrm{mM} \mathrm{NaCl}(\mathbf{b})$, and the amount of glucose released from the liposomes was measured. The amount of glucose released by $1 \%$ Triton X-100 was defined as $100 \%$. Peptide $3 ; O$, peptide $\mathrm{S} 3 ; \boldsymbol{\square}, \boldsymbol{\alpha}$-lactalbumin (as a negative control).

was investigated using $E$. coli-type liposomes with entrapped glucose and measuring glucose leaked into the buffer solution after incubation with the peptides. When incubated under lowionic-strength conditions, peptide 3 effectively caused leakage of glucose from the liposome preparation (Figure 3a). In the presence of $130 \mathrm{mM} \mathrm{NaCl}$, however, glucose leakage was reduced to about one-fifth (Figure 3b). The level of leakage caused by synthetic peptide S3 was similar to that of natural peptide 3, suggesting that $\mathrm{O}$-glycosylation of the peptide is not important for interaction with the liposomal membrane.

\section{DISCUSSION}

Three novel antibacterial peptides were isolated from the haemolymph of immunized $B$. mori larvae. We propose the name lebocin for these novel peptides (peptides 1,2 and 3 corresponding to lebocin 1, 2 and 3 respectively). As shown in Figure 4, the

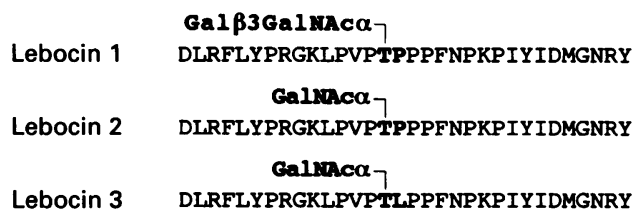

\section{Figure 4 Primary structures of lebocin 1, 2 and 3}

Structural differences are indicated in bold. primary structures of lebocin 1 and 2 differ only in their sugar moiety, suggesting that they are at different stages of sugar-chain elongation or degradation. Lebocin 3 has the same structure as lebocin 2 except that residue 16 is leucine instead of proline. This can be explained by one base substitution at that codon on the peptide gene. Thus there must be at least two lebocin genes. The amount of lebocin 1 recovered was low compared with that of lebocins 2 and 3, and we did not find any peptide with a disaccharide bound to the peptide moiety of lebocin 3 .

Lebocin can be classified into the insect proline-rich antibacterial peptide group [3]. Apidaecin [25] and abaecin from the honeybee, drosocin from the fruit fly [26] and pyrrhocoricin from the sap-sucking bug [27] are other known members of this group. Of these, drosocin and pyrrhocoricin have O-glycosylated threonine residues $[26,27]$. The threonine residue of abaecin appears to be unmodified because of the high yield of phenylthiohydantoin-threonine found in Edman degradation [15]. The insect antibacterial peptide that showed the highest $(41 \%)$ identity with lebocin was abaecin and this was achieved by introducing three continuous gaps into the lebocin sequence (Figure 5). We prefer to separate the proline-rich peptide group into two subgroups, one consisting of relatively short (18-20 amino acid-long) peptides (apidaecin, drosocin and pyrrhocoricin) and one consisting of longer (32-34 amino acid-long) peptides (abaecin and lebocin), for the following reasons. (1) The sizes of the amino acid sequences within each group are similar and different from the other subgroup. The peptides in the latter group are more than 10 amino acids longer, i.e. about half as long again as those in the first group. (2) The peptide sequences show relatively high identity with members of the same subgroup; lebocin has $41 \%$ identity with abaecin as described above, and drosocin has $47 \%$ and $53 \%$ identity with apidaecin (by introducing four continuous gaps) and pyrrhocoricin respectively. (3) The antibacterial activity of abaecin and lebocin, members of the longer-peptide subgroup, was suppressed even by physiological concentrations of salt, whereas no such phenomenon was observed with members of the shorter-peptide subgroup. (4) The bactericidal mechanism of lebocin appears to be different from that of apidaecin. Apidaecin completely lacks the ability to affect membrane permeability and its activity is not enhanced by detergent [28]. The D-enantiomer of apidaecin has no antibacterial activity, suggesting the involvement of stereoselective recognition steps in killing bacteria [28]. In contrast, lebocin can probably affect membrane permeability, as it strongly affected the membrane permeability of a liposome preparation under low-ionic-strength conditions and had a slight effect at physiological ionic strength (Figure 3). The antibacterial activity of lebocin against Acientobacter sp. was increased when inhibition-zone-assay plates contained $1 \%$ Triton $\mathrm{X}-100$ (results not shown), also suggesting that lebocin affects bacterial membrane permeability, as observed with attacin, an antibacterial peptide from $H$. cecropia [29].

Our results with the growth-inhibition-zone assay suggest that O-glycosylation of lebocin is important for expression of antibacterial activity (Table 3 ). In contrast, O-glycosylation appeared not to be important for increasing liposomal membrane permeability, in spite of low or physiological ionic-strength conditions (Figure 3). Marked differences between the two assay systems are (1) the former used live bacterial cells and the latter used an artificial phospholipid bilayer, and (2) the former contained agarose to solidify the plates. One possible explanation for the results is that O-glycosylation does not affect permeation of a simple phospholipid bilayer, but does affect permeation of bacterial membrane, because of, for example, the barrier presented by the lipopolysaccharide sugar chain on the outer 


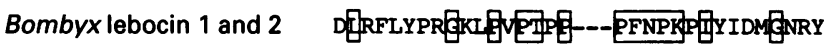 \\ Apis abaecin}

\section{Figure 5 Comparison of amino acid sequences in lebocins and abaecin}

The sequence of abaecin was taken from [15]. Gaps are introduced to obtain the highest identity, and identical residues are boxed. The threonine residues of the lebocins are 0-glycosylated.

membrane of Gram-negative bacteria. Another explanation is that the tertiary net structure of agarose in the assay plates affects the diffusion of glycosylated and non-glycosylated lebocins differently.

Lebocins do not seem to work alone in vivo as antibacterial peptides, as they do not show full activity at physiological ionic strength as is the case for abaecin [15]. Recently, a cDNA encoding lebocin 1 and 2 was isolated, and the mRNA of these peptides was confirmed to be induced by bacterial infection (S. Chowdhury, K. Taniai, S. Hara et al. unpublished work), suggesting that lebocins play some role in self-defence mechanisms against bacterial infection. This observation leads us to speculate that lebocins are involved in self-defence in co-operation with other antibacterial peptides of $B$. mori, because insects simultaneously produce several kinds of antibacterial peptides [3]. If there are factors present that cause low local ionic-strength conditions, by capturing ions for instance, lebocins may be the antibacterial peptides brought into action. An investigation of the role of lebocins in vivo is now in progress in our laboratories.

We thank Emiko Yamazaki of the Research and Development Division, Kikkoman Corp. for amino acid analysis, Dr. Subrata Chowdhury, Dr. Shigetaka Ishii and Dr. Hiroshi Sekine in our laboratories for helpful discussions and Ichiro Shiga for technical assistance. This work was partly supported by a special co-ordination fund for promoting science and technology (SCF) in the basic research core system by the Science and Technology (STA), Japan and by a Grant-in-Aid (Bio Media Program) of the Ministry of Agriculture, Forestry and Fisheries, Japan (BMP 95-V-1-5-9).

\section{REFERENCES}

Boman, H. G. and Hultmark, D. (1987) Annu. Rev. Microbiol. 41, 103-126

2 Kimbrell, D. A. (1991) BioEssays 13, 657-663

3 Hultmark, D. (1993) Trends Genet. 9, 178-183

4 Daher, K. A., Selsted, M. E. and Lehrer, R. I. (1986) J. Virol. 60, 1068-1074

5 Selsted, M. E. and Harwig. S. S. L. (1987) Infect. Immun. 55, 2281-2286

6 Lichtenstein, A. K., Ganz, T., Nguyen, T.-M., Selected, M. E. and Lehrer, R. I. (1988) J. Immunol. 140, 2686-2694

7 Lehrer, R. I., Barton, A., Daher, K. A., Harwig, S. S. L., Ganz, T. and Selsted, M. E. (1989) J. Clin. Invest. 84, 553-561

8 Sparkes, R. S., Kronenberg, M., Heinzmann, C. et al. (1989) Genomics 5, 240-244

9 Lambert, J., Keppi, E., Dimarcq, J.-L. et al. (1989) Proc. Natl. Acad. Sci. U.S.A. 86 262-266

10 Lee, J.-Y., Boman, A., Chuanxin, S. et al. (1989) Proc. Natl. Acad. Sci. U.S.A. 86 9159-9162

11 Hara, S., Taniai, K., Kato, Y. and Yamakawa, M. (1994) Comp. Biochem. Physiol. 108B, 303-308

12 Teshima, T., Ueki, Y., Nakai, T., Shiba, T. and Kikuchi, M. (1986) Tetrahedron 42 , 829-834

13 Tu, Y.-Z., Qu, X.-M. and Xu, T.-S. (1989) Sci. China Ser. B32, 1072-1081

14 Powning, R. F. and Davidson, W. J. (1973) Comp. Biochem. Physiol. 458, 669-686

15 Casteels, P., Ampe, C., Riviere, L. et al. (1990) Eur. J. Biochem. 187, 381-386

16 Yamakawa, M., Shirata, A., Taniai, K. and Miyamoto, K. (1990) Agric. Biol. Chem. 54, 2175-2176

17 Hultmark, D., Engström, A., Bennich, H., Kapur, R. and Boman, H. G. (1982) Eur. J. Biochem. 127, 207-217

18 Schägger, $H$. and von Jagow, G. (1987) Anal. Biochem. 166, 368-379

19 Suzuki, J., Kondo, A., Kato, I., Hase, S. and Ikenaka, T. (1991) Agric. Biol. Chem. 55, 283-284

20 Yamada, K. and Natori, S. (1994) Biochem. J. 298, 623-628

21 Peterson, G. L. (1983) Methods Enzymol. 91, 95-119

22 Endo, Y. and Kobata, A. (1976) J. Biochem. (Tokyo) 80, 1-8

23 Kadowaki, S., Ueda, T., Yamamoto, K., Kumagai, H. and Tochikura, T. (1989) Agric. Biol. Chem. 53, 111-120

24 Christensen, B., Fink, J., Merrifield, R. B. and Mauzerall, D. (1988) Proc. Natl. Acad. Sci. U.S.A. 85, 5072-5077

25 Casteels, P., Ampe, C., Jacobs, F., Vaeck, M. and Tempst, P. (1989) EMBO J. 8 2387-2391

26 Bulet, P., Dimarcq, J.-L., Hetru, C. et al. (1993) J. Biol. Chem. 268, 14893-14897

27 Cociancich, S., Dupont, A., Hegy, G. et al. (1994) Biochem. J. 300, 567-575

28 Casteels, P. and Tempst, P. (1994) Biochem. Biophys. Res. Commun. 199, 339-345

29 Engstöm, P., Carlsson, A., Engstöm, Å., Tao, Z.-J. and Bennich, H. (1984) EMBO J. 3, $3347-3351$

Received 3 January 1995/25 April 1995; accepted 12 May 1995 